\title{
Fostering equitable access to quality preschool education in India: challenges and opportunities
}

\author{
Nirmala Rao ${ }^{1 *} \mathbb{D}$, Namita Ranganathan², Ravneet Kaur² and Rashi Mukhopadhayay ${ }^{2}$
}

\author{
${ }^{*}$ Correspondence: \\ nrao@hku.hk \\ ${ }^{1}$ Faculty of Education, The \\ University of Hong Kong, \\ Pokfulam Road, Hong Kong, \\ Hong Kong \\ Full list of author information \\ is available at the end of the \\ article
}

\begin{abstract}
This paper focuses on the provision of center-based preschool education for children ranging in age from 3 to 6 years in India. It estimates access rates to various services and highlights issues related to equitable access to preschool services and the quality of preschool education. While India has made great strides in improving access to preschool education, numerous challenges have to be addressed to enhance its quality. The National Educational Policy 2020 and the country's commitment to meet UN Sustainable Development Goal Target 4.2 by 2030 and ensure that all girls and boys have access to quality pre-primary education provide opportunities to ensure equitable access to quality preschool education. Central to meeting national targets is the enforcement of the National Quality Standards for Early Childhood Care and Education. Further, increased budget allocations to preschool education, prioritizing professional preparation of the early childhood work force and harnessing technology to monitor government programs have considerable potential to enhance the early childhood system.
\end{abstract}

Keywords: India, Preschool education, Access, Equity, Quality

\section{Introduction}

The Lancet Series on Advancing Early Childhood Development estimated that in 2010, about 250 million children under the age of 5 years living in low- and middle- income countries were not reaching their developmental potential because of extreme poverty or stunting (Black et al., 2017). India had the largest number of these children in the world (63.4 million). Although the number of children at risk for poor development in 2010 was substantially lower than the 81.53 million in 2004, effective interventions for the most disadvantaged children in the world are critical (Lu et al., 2016). The Lancet Series also stressed the importance of interventions that integrate nurturing care and protection for promoting child development in the early years (Britto et al., 2017). Underpinned by robust empirical data, the international community has adopted the nurturing care framework (Nurturing Care for Early Childhood Development, 2018) and stressed the importance of investment in the early years (G20 Development Working Group, 2018). While the nurturing care framework focuses on children under 3 years, it 
recognizes the importance of preschool experiences in the development of children over 3 years.

A large body of evidence has shown that preschool attendance is positively associated with both cognitive and non-cognitive skills development in developing and developed countries (McCoy et al., 2017; Nores \& Barnett, 2010; Rao et al., 2017). Further, children who attend early childhood programs are less likely to drop out of school than other children. Hazarika and Viren (2013) found that children, ranging in age from 7 to 18 years, were more likely to be enrolled in school, in the Indian states of Bihar and Uttar Pradesh, if they had attended early childhood programs. We also know that the quality of early childhood services is positively related to child outcomes over time in low- and middleincome countries (Britto et al., 2017; Rao, 2010; Rao et al., 2012). This paper focuses on issues related to equitable access to preschool education in India a country that operates one of the world's largest educational systems and has the largest proportion (18\%) of the world's children under 5 years of age (UNDP, 2017).

In India, the term early childhood care and education (ECCE) is used to refer to all care and education services provided for children below 6 years. Our paper focuses on services for 3- to 6 year-olds which we refer to as preschool education (PSE). First, we provide an introduction to the context of PSE, highlighting the need for early childhood services and address issues related to access and equity. We particularly focus on the inclusion of groups that have been historically under-represented in preschool education. The term inclusion is typically used in relation to the education of children with special educational needs. Internationally, it is also used to refer to the inclusion of typically developing children who may also be excluded from education because of their social background, class, gender or ethnicity (Ainscow, 2020). Within the Indian context, the National Educational Policy 2020 (Government of India, 2020) also uses the term inclusion to refer to policy goals related to access to education of Underrepresented Groups. Underrepresentation in education may be a function of gender, caste, religion, migration, minority status, special needs or socio-economic status. Second, we provide an overview of the various types of preschool educational services available in the country from publicly funded to for-profit services available for young children. We also provide estimates of access rates to these services, disaggregated by family wealth, region of residence and caste when available. Third, we illustrate issues with the quality of centerbased preschool services. Finally, we address challenges and opportunities for the PSE system in India.

\section{Review}

\section{Country context}

\section{Demographic context}

The world's second most populous country, India had a population of about 1.33 billion in 2017 (World Bank, 2019a) and sustains nearly 18\% of the global population (Government of India (GOI), 2017). About 33\% of its population lives in urban areas (UNICEF, 2017). The country had 158 million children under the age of 6 and about 26 million births in 2015. In 2016, India had an under 5 mortality rate of 43, and 38\% (31\% urban; $41 \%$ rural) of children under 5 years were stunted. About $21 \%$ of the population was below the international poverty line (GOI, 2018a). The 2011 national census estimated 
that $13.1 \%$ of India's total population was under 6 years of age. Several characteristics of the Indian population affect the provision of early childhood services. According to the 2011 census, the child sex ratio (birth to 6 years) was 919 females per thousand males which was noticeably lower than the 927 females to 1000 males in 2001 (GOI, 2014). This illustrates the strong and persistent boy-preference in society. Girls are much more likely to get neglected and boys are likely to receive higher quality education than girls when family resources are constrained (Pande \& Malhotra, 2006).

Population growth also affects early childhood provision. There was a minimal increase of $0.4 \%$ from 163.8 million in 2001 to 164.5 million in 2011 in the birth to 6 years age group and the birth rate shows a declining trend (GOI, 2019a). There has been a concomitant decrease in the overall fertility rate from 2.6 in 2011 to 2.3 in 2017, a decrease in the adolescent fertility rate (births per 1000 women ages 15-19) from 67 in 2000 to 36 in 2010 and 23 in 2017 (GOI, 2019b) and increases in primary and secondary school completion rates (World Bank, 2019b). The above indicators suggest that young children have older and more educated mothers. Evidence suggests that more educated mothers are more likely to seek preschool services for their children than those with no education (GOI, 2016). Further, with urbanization, population growth is higher in urban areas than in rural areas suggesting the need for more services in urban areas.

\section{Cultural historical context}

India's cultural and historical context continues to influence equitable access to ECCE as it has a strong influence on the social and cultural capital and disposable income available to the parents of preschool children. India is a large developing country. In 1947, the country became independent of colonial rule and became the world's largest democracy. India has made great strides in reducing poverty and enhancing literacy in the past decades. Despite these impressive gains, the country has trailed behind comparable countries on economic and human population indices that are typically used to measure development. The low rate of progress has been ascribed to issues related to diversity, inequality, and the lack of attention to policy implementation as well as to the country's colonial heritage. In terms of diversity, India has 22 official languages and four major religious groups. ${ }^{1}$ The variations in socio-contextual, linguistic and topographical contexts within the country have posed challenges for ensuring access to ECCE and a "one size fits all" approach has not worked.

Historically, inequality stemming from social class and caste divides ${ }^{2}$ affected access to ECCE. Caste has been considered a proxy for socio-economic status (SES) and poverty (Nayar, 2007) and continues to be a matter of great consequence in India. Scheduled Castes, Scheduled Tribes, and Other Backward Classes are terms used to denote social groups. These groups qualify for the government's affirmative action schemes under India's reservation policy for historically disadvantaged social groups. It should be noted that the government does not collect information about caste in the national census but

\footnotetext{
${ }^{1}$ According to the 2011 National Census, about $80 \%$ of the population were Hindus. The rest were Muslims (14\%); Christians (2\%); Sikhs (2\%) and Others (2\%).

2 The four castes of the Hindus are the Brahmins (priestly class); Kshatriyas (rulers and warriors); Vaishyas (traders); and the Shudras (workers). The Scheduled Castes (Dalits) and Scheduled Tribes fall outside the caste system.
} 
respondents are asked to indicate membership of Scheduled Class and Scheduled Tribe groups. $^{3}$

Social class impacts on access to and nature of ECCE services afforded to young children. On one hand, in some countries the government provides free services to poor families (e.g., Head Start in the US or Sure Start in the UK) while more wealthy parents have to pay for ECCE. On the other hand, in some countries children from poor families do not receive any ECCE services as their parents cannot afford to pay for them or receive ECCE of a lower quality than their more advantaged peers.

In India, caste and SES affect ECCE. Using data from the Indian Human Development Survey, Bharti (2018) examined the relation between SES and Caste ${ }^{4}$ and found large inequality with Forward Caste groups much more likely to have more family wealth than historically disadvantaged social groups. Hence, any discussion of equity of access to ECCE in India cannot disregard the notion of caste and class. Children from certain groups and/or poor families are disadvantaged right from the prenatal stage. For example, based on a systematic review of studies from India, Sanneving et. al. (2013) concluded that economic status and registered caste or tribe were associated with access to maternal and reproductive health care. Indeed, the National Family Health Survey-4 (International Institute for Population Sciences and ICF, 2017) found higher early childhood mortality rates for Scheduled Caste and Other Backward Community groups than Forward Caste groups.

\section{Child health indicators}

Significant improvements in infant and child health in the country have been documented in National Family Health Surveys (International Institute for Population Sciences and ICF, 2017). In 2015-16, there was a higher percentage of child births in health facilities (79\%) than in 2005-06 (39\%). There were also increases in birth registrations (from $41 \%$ in $2005-06$ to $80 \%$ in 2015-16). Between 2005-06 and 2015-16, there was a decrease in infant mortality ( 57 to 50 per 1000), child mortality (74 to 50 per 1000), stunting (48\% to $38 \%)$ and underweight (43\% to $36 \%$ ) rates (International Institute for Population Sciences and ICF, 2017). Despite these improvements, the number of children suffering from poor health and nutritional deficiencies in India remains very high and 45 to 63.4 million children under 5 years are considered at risk for poor development because of poverty and/or stunting (Lu et al., 2016; Nurturing Care for Early Childhood Development, 2018).

\section{Socio-economic context}

India has one of the fastest growing economies in the world with a GDP growth of 7\% in 2018 (World Bank, 2019b). However, progress in terms of child development indicators has been much slower in India compared to many countries with similar or lower levels of economic growth. Limited priority is given to social sectors such as education, health,

\footnotetext{
${ }^{3}$ According to the 2011 National Census, Scheduled Castes and Scheduled Tribes were about $16.2 \%$ about $8.2 \%$, respectively, of the total population.

${ }^{4}$ He estimated that about $21.8 \%$ of the population were Scheduled Castes; $8 \%$ were Scheduled Tribes; $42.78 \%$ were Other Backward Classes; $19.76 \%$ were Forward Classes including 4.86\% Brahmins; $14.7 \%$ were Muslims; and 1.47\% were classified as Others.
} 
and nutrition in the national and state budgets (Das \& Kundu, 2014). Government expenditure to promote child development is far below levels that one would expect based on the articulated policy, vision for children and the fact that a relatively large proportion of population are children. In 2018-19, only 3.24\% of the union (national) budget was allocated for the birth to 18 age group and there has been a consistent decline in the percentage of the budget allocated to children from 2012 to 2013. Of this $3.24 \%$, the largest part (2.25\%) was earmarked for education (HAQ Centre of Child Rights, 2019). As compared to the 2017-2018 national budget, there was an increase in allocation in $2018-2019$ by $166 \%$ to the National Nutrition Mission and by $5 \%$ to the Mid-Day Meal scheme, highlighting the importance given to nutrition (HAQ Centre for Child Rights, 2019). Government budgetary allocations to preschool education reflect the priority or otherwise accorded to the sector. For example, the government has yet to invest in a system of monitoring preschool quality.

\section{Policy context}

Globally, the importance of the early childhood period for human and societal development is reflected in the United Nations Sustainable Development Goal (SDG) Target 4.2 (by 2030, all girls and boys have access to quality early childhood development, care and education so that they are ready for primary education). The Constitution of India guarantees fundamental rights to all children in the country and empowers the State to make special provisions for children in its several articles. Numerous government education policies, acts and programs ${ }^{5}$ reflect the priority given to child protection and to promoting child development and education. Amendments to the Indian constitution in the past decade show that India has committed to a rights-based structure and the central and state governments have increased their legal obligations to children. For example, The Right of Children to Free and Compulsory Education Act, 2009 (Right to Education Act) (GOI, 2009) mandates that every child has a right to full-time basic education of a reasonable quality. Subsequent amendments of the Right to Education Act in 2017 and 2019 (GOI, 2019c) highlight recognition of the need to make legal changes to promote education. Another example of the commitment to a rights-based approach is the National Food Security Act (Right to Food Act) that was passed in 2013 (GOI, 2013a). The Act deems that about $75 \%$ and $50 \%$ of the rural and urban population, respectively, has a legal entitlement to food. Particularly relevant for child development is that pregnant and lactating women are entitled to a free meal and cash transfer and children aged 6 months to 14 years are provided a free meal.

Equity cannot be achieved without an articulated and implemented government policy. The constitution of India supports the notion of inclusion and prohibits discrimination based on religion, ethnicity, caste and sex (GOI, 2018b) and the Ministry of Women and Child Development (MWCD) clearly states that it wishes to promote the holistic development of children belonging to all ages, castes, religions, language groups,

\footnotetext{
${ }^{5}$ National Policy for Children, 1974 and 2013; National Policy for Education, 1986; Accession to UN CRC, 1992; National Nutrition Policy 1993; National Health Policy, 2002; National Charter for Children, 2003; National Plan of Action for Children, 2005 and 2016; Adoption of Guidelines for NCPCR, 2011 and 2015; National Early Childhood Care and Education (ECCE) Policy 2013; National Early Childhood Care and Education (ECCE) Policy 2013; National Early Childhood Care and Education (ECCE) Curriculum Framework 2013.
} 
communities, socio-economic status and geographical locations. Indeed, Indian government policy has a strong focus on the inclusion of children from scheduled castes and tribes and the caste-based affirmative action policy was mentioned earlier. It should be noted that more recent national educational policies also give priority to inclusion of children with special needs and there is also a focus on gender-inclusion to mitigate gender gaps in participation in education (GOI, 2018c).

In recent years, India has made significant progress with respect to strengthening the policy framework for ECCE. The Government of India released the National ECCE Policy in 2013 (GOI, 2013b), a National ECCE Curriculum Framework (GOI, 2013c) and the Quality Standards for ECCE (GOI, 2013d). Together, these documents provide a comprehensive framework for promoting access, equity and quality in ECCE. State governments have designed their own curricula in light of this national framework. The documents do not fully acknowledge the large variations across and within states in child outcomes. The Commission for Protection of Child Rights has developed regulatory guidelines for private preschools for 3- to 6-year-olds (GOI, n.d.). That stated, given the high rates of poverty and stunting in India, a concerted effort has to be made to address access, equity, and the quality of preschool provision to ensure that the country can meet the SDG Target 4.2.

\section{Public investment}

Indicators of children's nutrition status, health and child mortality rates provide strong evidence that public investment to promote ECCE falls short of what is required to meet aspirations for children based on the UN Sustainable Development goals. Currently the country is far from the targets for Goal 1-no poverty, Goal 2-zero hunger, Goal 3good health and well-being, and Goal 4-quality education (GOI, 2018c). Hence, public policy has not been thus far properly implemented and public funding does not match policy intent. Das and Kundu (2014) make a strong case for increased public investments in ECCE and analyze some of the reasons that states do not utilize all allocated funding for ECCE.

\section{Governance}

The MWCD has the major responsibility for pregnant women and for children from birth to 6 years, which includes ECCE. Given the integrated nature of ECCE and crosssectorial policies, the Ministries of Health and Family Welfare, Human Resource Development, and Social Justice and Empowerment are also involved in ECCE. It should be noted that the government has restructured many of its schemes to enhance their impact. For example, child-focused schemes to improve health, nutrition, and ECCE, to ensure child protection and to empower adolescents have been consolidated under the 'Umbrella Integrated Child Development Services' Scheme (Government of India, 2019d). The restructuring and rationalization of the thousands of government schemes to promote early development may result in economies of scale and increased efficiencies and effectiveness.

A minimalist approach to the governance of public sector programs and a laissezfaire attitude to monitoring private sector programs that espouse developmentally inappropriate practices are evident. However, a concern that the absence of any regulatory 
mechanisms may let the private sector (by virtue of its volume) determine norms and expectations for ECCE led to the development of National Quality standards in ECCE (GOI, 2013c). While public sector programs are inspected, to date there is no systematic monitoring of whether private sector programs are adopting these standards. Developing a strong regulatory mechanism is a key challenge to ensuring quality ECCE programs nationwide (Krishnakumar, 2016). There is a clear need to monitor programs systematically, provide incentives for them to improve and censure those that do not meet the standards.

\section{Access to PSE}

Government policy documents reiterate that all children have a right to access ECCE (e.g., GOI, 2013b). While ECCE covers the age range from birth to 8 years, the focus of this paper is 3- to 6-year-olds. Center-based ECCE for children, ranging in age from 3 to 6 years, is provided by the government, non-governmental organizations (NGOs) and private for-profit institutions, and there is a great diversity in the nature and underlying philosophy of programs (GOI, 2013c). A variety of terms is used to denote these programs: Anganwadis (courtyard centers operated under the government's flagship, Integrated Child Development Services (ICDS) scheme), Balwadis, Crèches, Playschools, Nurseries, and Preschools, Further, Lower Kindergarten (LKG) and Upper Kindergarten (UKG) classes exist in some government, aided or private primary schools. The different terms used to denote ECCE are a reflection of variations in the foci of services and the age group covered. For example, Anganwadi Centers (AWCs) provide holistic and converging services in health, nutrition, family care, education, and social protection for children from birth to 6 years. On the other hand, the LKG and UKG classes typically aim to prepare children for formal primary education.

Data on enrollments suggest that the initiatives of the government, NGOs, and private institutions have led to increased access to center-based PSE over time and that the majority of 3- to 6-year-olds enrolled in some form of ECCE (Bhattacharjea \& Ramanujan, 2019; GOI, 2016. Kaul, 2019a; Rao \& Kaul, 2018). We first provide an overview of the services available followed by estimations of access rates to them.

\section{Government-funded programs}

Various education policies and programs illustrate the emphasis placed by the government on holistic ECCE. In 2009, approximately 130 programs under various departments and ministries aimed to promote development of children from birth to 6 years (Kaul \& Sankar, 2009). The major public program that focuses on 3- to 6-year-olds is the ICDS. This scheme was initiated in 1975, and in 2018 there were 1,363,000 AWCs operating in the country (GOI, 2018d). An evaluation of the functioning of AWCs was undertaken by the government (Niti Aayaog) in 2015 (GOI, 2015). Results indicated that $68.6 \%$ of AWCs were providing interventions to handle child malnutrition. However, $22.5 \%$ of AWCs did not have the required medication to treat children who were ill. Observations revealed that only $59 \%$ of the AWCs had adequate space, and thus the remaining $41 \%$ had either inadequate or unsuitable accommodation. Through the years, the AWCs have also been faulted for not giving enough attention to PSE (Rao \& Kaul, 2018). 
Government primary schools also have age-segregated LKG and UKG classes. Official data on enrollment in these classes are hard to access as the MWCD has responsibility for children from birth to 6 years and does not include data on enrollment of children in primary schools. On the other hand, the Ministry of Human Resource Development reports data on enrollment from Primary 1. Hence, children below 6 years in primary schools are not enumerated in the surveys of educational institutions. However, household surveys do provide information on enrollment of children in different services. Studies have indicated that preschool-aged children are over-age or underage for the class in which they are enrolled (Alcott et al., 2018; Kaul et al., 2017). Notably, the Annual Status of Education Report 2018 (Rural) (ASER, 2019) required responses to questions related to whether 3- to 6-year-olds were in preschools and/or schools and the grade they attended (Bhattacharjea \& Ramanujan, 2019). Further, the government's Samagra Shiksha that endeavors to consider preschool to Class 12 as school education and to support states to provide PSE (GOI, 2018d) may result in a veritable account of access to PSE at the national level.

\section{Non-government organizations}

Non-governmental organizations play a crucial role in providing ECCE to children from disadvantaged backgrounds utilizing local resources. Two long-established, respected NGOs providing ECCE are Mobile Crèches and Pratham. The Mobile Crèches organization has focused on the provision of ECCE at construction sites to young children of construction workers. These children have typically accompanied their parents who have migrated to cities from rural areas (Bajaj \& Sharma, 2016). Pratham's Early Childhood Education programs focus on promoting the holistic development of children ranging in age from 3 to 6 years. This is done through the provision of direct services or through supporting Anganwadis or preschool classes in government primary schools. In 2017-18, about 610,000 children benefitted from Pratham's ECE programs. About 15,000 received direct services, and about 68,000 benefitted from Pratham's Anganwadi Support program while another 527,000 children were reached through Pratham's partnership with state governments (Pratham, 2019).

\section{Private initiatives}

Data from a nationally representative sample, collected in 2013-2014, indicate that about 31\% of 3- to 6-year-olds receive PSE from private, for-profit centers. Private preschools are not regulated by the government and there has not only been a rapid proliferation of private preschools in urban areas but an unprecedented expansion of low fee preschools in remote rural and tribal areas. The physical settings of these private preschools range from one-room tenements to remarkable preschools equipped with the latest equipment and professionally qualified staff (Singh \& Mukherjee, 2017).

\section{Enrollment rates}

While data on enrollments in publicly funded ECCE programs are available, recent statistics on attendance in programs run by NGOs and private organizations are not available (GOI, 2013c). Table 1 estimates enrollments from various sources. The best estimates on enrollments in ECCE for 3- to 6-year-olds in the country come from the national 
Table 1 Number of early childhood centers and estimated enrollment

\begin{tabular}{|c|c|c|c|}
\hline Types of centers & Number of centers & $\begin{array}{l}\text { Percentage } \\
\text { of enrollment } \\
\text { ( } 3-6 \text { years) }\end{array}$ & $\begin{array}{l}\text { Type of service (monitoring } \\
\text { body) }\end{array}$ \\
\hline $\begin{array}{l}\text { Anganwadi centers under the } \\
\text { ICDS }\end{array}$ & $1,363,000^{\mathrm{a}}$ & $39^{c}$ & $\begin{array}{l}\text { Preschool education component } \\
\text { of ICDS } \\
\text { Focus on play-based learning; } \\
\text { mixed age grouping (Ministry } \\
\text { of Women and Child Develop- } \\
\text { ment) }\end{array}$ \\
\hline $\begin{array}{l}\text { LKG and UKG classes in govern- } \\
\text { ment primary schools }\end{array}$ & N.A & N.A & $\begin{array}{l}\text { LKG/UKG/KG classes } \\
\text { Academic focus; classes may be } \\
\text { age-segregated (Department of } \\
\text { School Education and Literacy, } \\
\text { Ministry of Human Resource } \\
\text { Development) }\end{array}$ \\
\hline Privately run preschools & $10,237^{b}$ & $31^{c}$ & $\begin{array}{l}\text { Nursery/LKG/UKG classes } \\
\text { Academic focus; age-segregated } \\
\text { classes (no monitoring body) }\end{array}$ \\
\hline ECCE offered by NGOS & N.A & N.A & (No monitoring body) \\
\hline Not attending any preschool & & $27^{c}$ & \\
\hline
\end{tabular}

Sources:

a Government of India (2018d)

${ }^{\mathrm{b}}$ Government of India (2015)

' Government of India (2016)

Table 2 Percentage of 3- to 6-year-olds receiving preschool education (2013-2014)

\begin{tabular}{lllll}
\hline & & Anganwadi center & Privately run center & Not attending \\
\hline Residence & Total & 38.7 & 30.7 & 27.1 \\
& Rural & 46.0 & 22.0 & 28.3 \\
\multirow{3}{*}{ Gender } & Urban & 22.2 & 50.4 & 24.5 \\
\multirow{3}{*}{ Social category } & Male & 37.5 & 31.7 & 27.4 \\
& Female & 40.1 & 29.6 & 26.9 \\
& $\mathrm{SC}^{\mathrm{a}}$ & 42.3 & 24.9 & 29.4 \\
& $\mathrm{ST}^{\mathrm{b}}$ & 52.0 & 17.4 & 26.9 \\
Wealth index & OBC & 35.9 & 31.9 & 28.3 \\
& Other & 34.3 & 39.3 & 23.6 \\
& Lowest & 51.9 & 8.6 & 34.8 \\
\hline
\end{tabular}

Source: Government of India (2016)

a Scheduled Caste

b Scheduled Tribe

c Other Backward Community

Rapid Survey on Children undertaken by the government in 2013-2014 and supported by UNICEF (GOI, 2016). The RSOC is a household survey that covered 28 states and Delhi and involved a representative sample of 105,483 households and 5630 AWCs. Findings indicate that overall, $38.7 \%$ of 3 - to 6 -year-olds attend AWCs and $30.7 \%$ of them attend private centers. On the other hand, $27.1 \%$ of 3- to 6-year-olds received no PSE (GOI, 2016).

Table 2 shows participation rates by area of residence, gender, social category and wealth index. Children from families in the highest wealth quintile $(80 \%)$ were more 


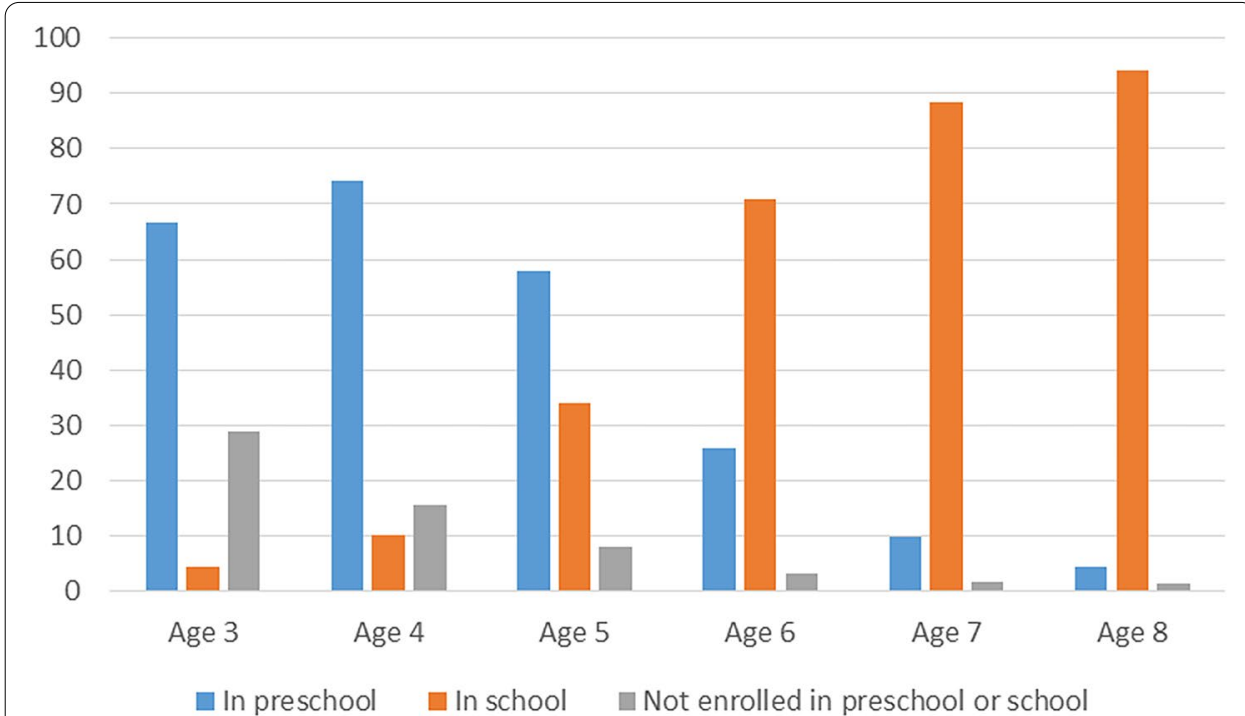

Fig. 1 Enrollment status of children from 3 to 8 years in rural India in 2018 (Source: ASER 2019)

likely to be attending preschool than those from the lowest wealth quintile (65\%). In terms of overall rates, there were few differences in rates based on area of residence and gender. Further, the majority of children from socially disadvantaged families were attending free government-funded AWC. This is very positive from the perspective of equity as children who need ECCE the most are availing of government services. Children who were from families in the highest wealth quintile were more likely to attend private programs $(61.5 \%)$ than children from families in the lowest wealth quintile (15.4\%). On the other hand, children from poor families were more likely to attend government programs that are free (51.4\%) than children from families which fell into the highest wealth bracket (15.4\%). Among children who did not receive PSE, 34.7\% came from the poorest families while $19.9 \%$ were from the wealthiest families.

The Annual Status of Education Report 2018 (Rural) (ASER, 2019) provides rich information about access to ECCE in rural areas as the sampling frame is based on the national census. As shown in Fig. 1, the ASER 2018 survey found that 71\% of 3-year-olds, $85 \%$ of 4-year-olds, $92 \%$ of 5 -year-olds, and $96 \%$ of 6 -year-olds were attending preschool or school. Hence, there is almost universal access to education by age 5 . Enrollment rates also increase as children mature. Figure 2 shows the types of preschool services received by children in the ASER survey. Notwithstanding large variations between states (Bhattacharjea \& Ramanujan, 2019), by age 6 the majority of children are in primary school, and the private unregulated market is a major provider of services for children aged 4 and above. Figures 1 and 2 also show about 5\% of 3-year-olds and 10\% of 4-year-olds are already enrolled in primary school and experiencing a curriculum that is not age-appropriate and not in keeping with policy directives (Bhattacharjea \& Ramanujan, 2019).

The India Early Childhood Education Impact study also provides information on access rates for 4-year-olds in 2014. This large-scale, seminal 5-year longitudinal study of 13,686 children in 362 villages in three Indian states found that about $80 \%$ of sampled 4-year-olds attended a preschool program (Kaul, 2019b; Kaul et al., 2017). 


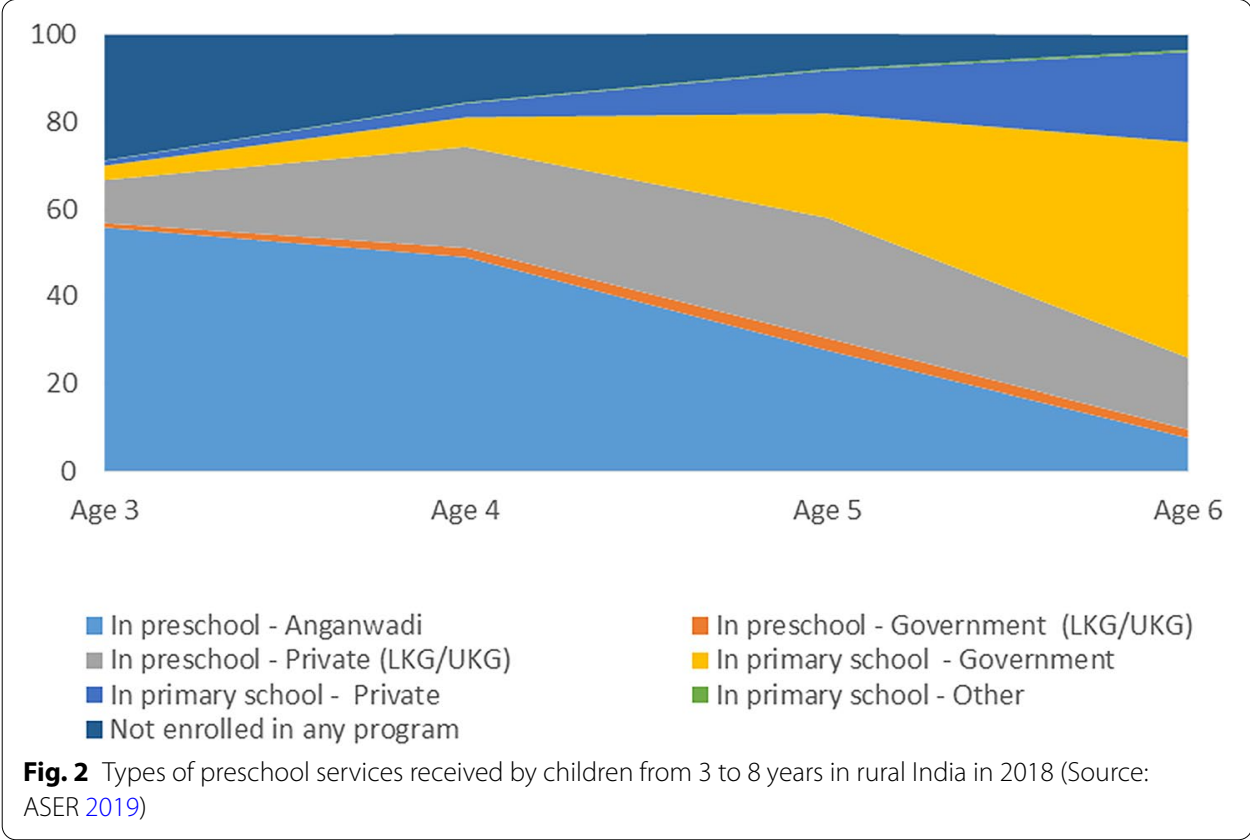

The data on access to ECCE also suggest that there may not be equitable access to quality ECCE. Based on data from the Young Lives longitudinal study, Singh and Mukherjee (2017) reported that among a sample of 1915 children from the state of Andhra Pradesh, 91.4\% attended preschool, with 41\% attending private preschools and about 50\% attending government preschools in 2006. Children from wealthier families attended private preschools at much higher rates than children from the poorest families. Further, boys are more likely to attend private ECCE centers than girls. Propensity score matching indicated that children who were in private preschools in 2006 scored nearly 10 times higher in mathematics and reported significant greater subjective wellbeing at age 12 than children who attended government preschools. It is very important to note that private ECCE centers catering to socially disadvantaged families have been mushrooming all over the county (Rao \& Sun, 2010), and that these centers tend to have an academic focus, engage in practices that are not in line with national guidelines and are considered developmentally inappropriate (Bhattacharjea \& Ramanujan, 2019; Kaul, 2019a). The issue of equitable access to quality will be considered further in the following section.

\section{Quality of ECCE}

\section{Measurement of ECCE quality}

The quality of center-based ECCE services has typically been assessed by considering both structural and process dimensions. Structural quality includes teacher academic and professional qualifications, adult-child ratios, group size and the physical setting. On the other hand, process quality is concerned with teacher-child interactions and educational activities. High structural quality (e.g., teacher professional qualifications, favorable teacher-child ratios) is assumed to set the stage for high process quality. The Indian Quality Standards for ECCE (GOI, 2013d) regard structural dimensions of quality 
including physical setting, staff training, and caregiver to child ratio as non-negotiable indicators of ECCE quality.

The Early Childhood Education Quality Assessment Scale (ECEQAS) (Kaul et al., 2017) has been used to evaluate the quality of center-based early childhood services in three states in India. The scale was used to observe classroom quality for 4-year-olds in 298 ECCE centers from the private, government and voluntary sectors in three states in India. The ECEQAS has 10 different domains that are rated based on classroom observation: Physical infrastructure and materials; Class management and organization; Language and reasoning experiences; Literacy and numeracy; Creative activities; Self-help skills; Fine and gross motor activities; Social development; and Teacher disposition. Results indicated that preschool quality was associated with children's school readiness (Kaul, 2019b).

Structural quality can be enhanced by increasing the stringency of requirements for the registration and operation of preschools, and process quality can be enhanced through professional development activities for teachers. For example, a large-scale study in Chile found that workshops and in-class coaching for kindergarten teachers had positive impacts on emotional support and classroom organization after 2 years of the program (Yoshikawa et al., 2015).

\section{Preschool quality and child outcomes}

Relatively few studies have assessed the relationship between ECE quality and child outcomes in developing countries. In Cambodia, China and India, Rao and colleagues reported that children who attended higher quality preschools showed better school readiness than those who attended lower quality preschools (Rao \& Sun, 2015). Britto et al., (2017) examined the effectiveness of early childhood interventions in low- and middle-income countries and concluded that both formal and non-formal ECCE programs enhanced cognitive and psychosocial development. The largest effects were associated with programs of higher quality regardless of program type as well as programs for vulnerable children. Preschool quality included consideration of the number, variety and type of materials, classroom organization, instructional support and engagement in interactive reading. Another review which included studies conducted in both developing and developed countries concluded that high quality ECE produces substantial economic benefits, including higher rates of primary and secondary completion, higher earnings in adulthood, and fewer incidences of criminal behavior (UN SDSN, 2014). However, there is a paucity of robust evidence on the long-term effects of early childhood interventions in low- and middle-income countries (Rao et al., 2017).

\section{Challenges and opportunities}

The foregoing sections have considered policies and schemes to promote PSE in India. Yet, there remain numerous unmet challenges in fostering equitable access to quality PSE. These include factors related to the supply of ECCE, the demand for specific types of services, the quality of services and its regulation and the policy context, which are discussed below. 


\section{Supply and utilization of ECCE}

Challenge 1: Scale Millions of children do not receive PSE (see Table 1) and the scale of supply needed is enormous. Even when free services are provided, they are not fully utilized. As noted earlier, PSE for all children aged 3 to 6 years remains an important component of the ICDS. The following observations from the Rapid Survey on Children undertaken in 2013-2014 (GOI, 2016) are significant in this regard. Among, the children who attended the ICDS, 58\% of children attended PSE for more than 16 days a month, however $40 \%$ of the children attended PSE just for 1 to $2 \mathrm{~h}$ per day and another $28 \%$ attended PSE for 2 to $4 \mathrm{~h}$ per day. The mean number of hours per day spent in PSE was 2.8 in both rural and urban areas. In terms of equitable access, more children from the lowest wealth quintile (47\%) attended PSE in the AWCs than those in the higher wealth quintiles; more rural children (43\%) attended PSE at AWCs than their urban counterparts (27\%); more children belonging to Scheduled Tribes (51\%) and Scheduled Caste groups (41\%) received PSE at AWCs than children from Other Backward Classes (35\%) and general castes (38\%) (GOI, 2016). The point to note is that although a substantial number of preschool children especially those from marginalized communities are receiving PSE at AWCs, an equally large number are not benefitting from these services.

\section{Opportunities}

The estimated growth of the PSE Market in India and the fact that it is a late entrant into the process of scaling-up access to PSE afford the country considerable opportunities to increase access to ECCE. In the 2017 financial year, the PSE market in India was estimated to be INR 130 billion (USD 1.83B) and was expected to grow at a rate of $20 \%$ per year until 2020 (CARE Ratings, 2018). The growth of preschools is assumed to be due to a combination of factors including urbanization, growth in maternal employment rates, increased family income, increases in private preschool chains and increased awareness of the importance of PSE (CARE Ratings, 2018). The relatively low initial level of access presents large opportunities for growth.

Access rates to ECCE have been increasing over the past decades and there is considerable potential to scale up implementation quality within the ICDS (Rao \& Kaul, 2018). However, being a late entrant into the area of actually implementing programs brings opportunities to benefit from the lessons learned in other countries and avoid the mistakes inadvertently made by other countries. For example, in many Euro-American contexts children with disabilities have been educated in segregated, integrated and inclusive classrooms, respectively (Chakraborti-Ghosh, 2017). India need not go through the stages of segregated and integrated provision for children with disabilities but focus on inclusive PSE right from the start.

Challenge 2: Diversity Diversity in terms of geographic terrain, types of ECCE programs, socio-demographic background of children served and state policies pose further challenges in meeting the needs of preschool aged children. The geographical terrain accompanied by poor infrastructure and transport in rural areas makes it difficult for the children to access ECCE in remote and tribal areas. Children may have to walk up and down the hills to reach an AWC, which can be up to a $\mathrm{km}$ from their homes. Further, high temperatures, monsoons, inadequate buildings and facilities compound accessibility 
challenges. Improvements in the physical conditions of the learning environments and in infrastructure may overcome the above-mentioned obstacles.

Private preschools that charge high fees and claim to meet global standards, private preschools that charge fees affordable to middle-class families, private preschools for the poor that charge relatively low fees, programs run by NGOS, and government-funded services co-exist. In addition, the heterogeneity of students in preschool classrooms, especially in cities, brings challenges to the early childhood teacher. He/she may have a classroom with first-generation learners and children from different regions, language groups, caste, social class and religious backgrounds. Further, there is variation in supply of and demand for ECCE across India's states. All these factors foreshadow the need to be mindful of diversity and responsive to contextual factors in developing and implementing policy to enhance equitable access to ECCE.

\section{Opportunities}

Improved transport and infrastructure will help overcome challenges brought about by the terrain is some parts of the country. Furthermore, elite private preschools have the opportunity to enhance the diversity of the student population by offering scholarships and recruitment lotteries. As discussed in the following sections, the country's commitment to the SDGs and the National Educational Policy 2020 provide opportunities to increase the supply of ECCE and access to PSE for under-represented groups. It is imperative that teachers are empowered to deal with diverse learners as discussed in the section on teacher quality below. The potential size of the PSE market affords opportunities to both the public and private sectors to increase the supply of ECCE and meet parental demand for services.

Challenge 3: Issues related to parental demand for ECCE In recent years, an increasing number of parents is sending their children to private preschools. The Indian Early Childhood Education Impact Study (Kaul et al., 2017; Kaul, 2019b) found that parents who could afford it, preferred sending their children to a private preschool which they perceive as having better quality. Parents also wish to send their children to English-medium private schools (Centre for Budget \& Policy Studies, 2018). The India Early Childhood Education Impact study also found that parents choose to send their children to preschool to prepare them for formal schools and to learn English (Alcott et al., 2019). It is imperative that parents are encouraged to choose to send their children to ECCE centers with trained teachers and appropriate learning environments and resources.

\section{Opportunities}

According to the 2020 National Educational Policy, the government plans to launch a large-scale media campaigns to generate demand for ECCE and promote learning at home. This will provide an opportunity to educate parents about developmentally and culturally appropriate PSE.

\section{Quality of ECCE services}

Challenge 4: Factors related to the location and physical conditions of the AWCs A number of factors related to the physical settings of the AWCs pose challenges to equitable 
access to quality ECCE. First, the location of the center does not always encourage access. AWCs are sometimes more than a kilometer away from children's homes and walking to the AWCs in hilly terrain or in the desert poses access challenges. Further, children from marginalized communities continue to be excluded from ECCE due to the location of the AWCs. In fact, in both rural and urban areas, the reason cited for not attending PSE at the AWC by almost one-fifth of families was distance from home (GOI, 2016). Second, AWCs have poor infrastructure and resources. About 39\% of 3- to 6-year-olds receive PSE in one of 1.3 million AWCs. However, national surveys indicate that the AWCs have poor infrastructure and facilities. About $65.5 \%$ of all AWCs functioned in one room while the rest had only two rooms. Only $52 \%$ of the AWCs had separate kitchens and in $15.9 \%$ of the AWCs, (supplementary) food for the children was cooked in the same room where PSE sessions were conducted. Only $43.4 \%$ of the AWCs had toilets in their buildings and only $32.4 \%$ had electricity connections (RSOC, 2013-14) (Government of India, 2016). There is also inadequate space for indoor and outdoor activities in both urban and rural AWCs (NIPCCD, 2006). Third, there is a lack of adequate educational resources in the AWCs. Several studies have pointed out the inadequacy of kits and play materials including toys, charts in the AWCs (Dhingra \& Sharma, 2011, Dixit et al., 2010, NIPCCD, 2006).

Recall that AWC are child care centers within the ICDS. There are several factors related to the ICDS program, the largest supplier of PSE. As noted earlier, the ICDS program aims to provide early childhood services that encompass health, nutrition and education in an 'integrated' manner. The larger objective is the holistic development of children. However, at the ground level, health and nutrition appear to receive more attention than education. In fact, one of the biggest challenges that remains is that ICDS is primarily perceived as a nutrition program, which has resulted in the rather inadequate prioritization of PSE and its implementation (Rao, 2005).

The National Early Childhood Care and Education (ECCE) Policy (GOI, 2013b) and the National Early Childhood Curriculum Framework (GOI, 2013c) promote the holistic development of children. Despite its earnest intention, it has remained a "hardly known document" (Pandya, 2018). The envisioned ECCE curriculum appears too standardized, losing sight of the need for local contextualization. Another curriculum-related issue is a tendency to address 3- to 6-year-olds as one age group which reflects a lack of appreciation of developmental differences within the 3 to 6 year age range.

\section{Opportunities}

The enhanced infrastructure and National Educational Policy discussed later are opportunities for development.

Challenge 5: Teacher quality There are numerous challenges associated with recruiting and retaining high-quality preschool teachers. Technically, a certificate or diploma in ECCE is required to teach at preschools and in 2010-2011, there were 124 teacher training institutions with an annual intake capacity of 5938 students providing pre-service training that is recognized by the National Council of Teacher Education (UNESCO, 2011). However, the provision of places cannot meet the demand for training the number of teachers required. The private sector thus often employs untrained teachers at low wages. 
Many AWCs follow the concept of a mother teacher wherein a woman from the local community who has completed Grade 5 can be employed as an Anganwadi Worker. She receives about 10 days of pre-service training which may be inadequate to support the facilitation of cognitive development and school readiness in the AWCs.

A major obstacle in the professionalization of ECCE teachers stems from the poor social status accorded to them. Further, the relative absence of men in this field has also contributed to the public perception of ECCE being a low status job. Moreover, the relatively low wages and remuneration given to ECCE professionals including the Anganwadi worker is very low and there is an absence of a career path.

\section{Opportunities}

A related significant development is the initiation of the 4-year Integrated Teacher Education Programme by the National Council of Teacher Education (GOI, 2019e). This program prepares students who have completed Grade 12 to be either primary or secondary school teachers. Completion of the 4-year double-degree teacher preparation program leads to a Bachelor's Degree in Liberal Arts and Education (BA BEd) or Basic Science and Education (BSc. BEd). The unique feature of these programs is that they accord equal status to primary and secondary school teachers. Moreover, teachers who take the primary level specialization will be qualified to teach children from 3 to 11 years which will support the transition of children from preschool to primary education. Further, having professionally qualified teachers may enhance children's school readiness and decrease the number of children who are not demonstrating age-appropriate learning outcomes in primary school.

Challenge 6: Monitoring, regulation and quality assurance of ECCE centers Although a mechanism for monitoring of service delivery exists, the quality of PSE in the AWC is not monitored regularly (NIPCCD, 2012), and there are no registration requirements for private preschools despite the burgeoning private preschool sector in both urban and rural areas (Kaul, 2019a). The quality of services provided by private ECE centers is variable. Some elite preschools provide high quality services while many preschools "affordable" to low- to middle-income families do not necessarily provide developmentally age-appropriate PSE and focus on the 3Rs (Kaul, 2019a). Prior to the issue of the National ECCE Policy (GOI, 2013b) and the subsequent Quality Standards Framework for ECCE (GOI, 2013d), there was a complete absence of any guidelines or quality standards for PSE.

This minimalist approach to accountability in the public sector and the laissez-faire attitude to private programs are detrimental to children's development and education. There appears to be a fear that in the absence of any regulatory mechanism, the private sector (by virtue of its volume) may start setting norms and expectations for PSE. Thus, as noted earlier, the development of a strong regulatory framework is necessary to ensure ECCE program quality across the country (Krishnakumar, 2016).

\section{Opportunities}

Once again, the National Educational Policy, if fully implemented will address this challenge. The Policy explicitly states that oversight of all preschool programs, regardless of whether they are operated by private, public or charitable organizations, will be 
covered by a regulatory and accreditation system. Furthermore, new technologies and partnerships between the government and private sector can enhance regulation of the preschool sector. The government has harnessed the power of technology to enhance monitoring of the functioning of AWCs. The use of digital tools such as the ICDSCommon Application Software enables real-time monitoring of the physical status of children (GOI, 2018e). This technology can be scaled up to monitor development and learning. The government has also entered into partnerships with private companies and NGOs to construct modern AWCs (KMPG, 2019).

\section{Policy context}

Challenge 7: Policy implementation As noted earlier, India's commitments to its youngest citizens are manifest in the Indian constitution and amendments made therein. India has numerous child-friendly policies. However, they are not fully implemented. One of several possible reasons for inadequate ECCE policy enactment arises from the division of responsibilities and funds between the Union (federal/central) and state governments. The Union and states have a joint responsibility for ECCE service delivery, which is undergirded by a plethora of policies and action plans. A consequence of this is that ECCE services are delivered through a rather piece meal approach. While the major responsibility for ECCE rests with the MWCD, other ministries including the Ministries of Health and Family Welfare, Human Resource Development and Social Justice and Empowerment are also involved in one way or the other, due to its integrated nature. One of the challenges in promoting holistic development of young children is the necessity of co-ordination between different ministries responsible for providing services to these children. ECCE is managed by the MWCD but Education is under the auspices of the Ministry of Human Resource Development and this has led to a fractured view of early learning with preschool children bearing the brunt of a tussle between two ministries to make rules, set standards and decide budgets for the present and future of these children. This division has adverse effects on the creation and implementation of policies to promote child development and learning.

The autonomy of states in the utilization of allocated funds for children has led to wide variations across states in the supply and demand for government-funded ECCE (Centre for Budget \& Policy Studies, 2018). For example, there are wide variations in utilization of PSE at AWCs across states (GOI, 2016). The percentage of children aged 3 to 6 years attending PSE at AWCs ranged from $1 \%$ in Nagaland to $74 \%$ in Tripura with a national average of $39 \%$.

\section{Opportunities}

The laudable National Educational Policy (GOI, 2020) recognizes ECCE as the foundation stage of learning and the policy goal is for every child ranging in age from 3 to 6 years to access free, safe, high quality developmentally appropriate care and education by 2025. Notably the Draft policy addresses issues with the split-phase and split-governance ECCE system and mandated the erstwhile Ministry of Human Resource Development (re-designated as the Ministry of Education) to oversee education for children from above 3 years, regardless of the setting in which ECCE is provided (e.g., AWCs, pre-primary class in a government school, private preschool center). Further, it states 
that an effective regulation/accreditation system to ensure quality ECCE will be implemented and that the regulatory system will cover public, private, and NGO preschools. If fully implemented, the National Policy will certainly foster equitable access to quality ECCE.

International commitments and national policy set the stage for India to meet its goals of providing equitable access to high quality PSE. India is committed to meeting the UN Sustainable Development Goal Targets and Target 4.2 states that by 2030 that all girls and boys should have access to quality pre-primary education. Government budgets actualize policy intent and increases in budget allocations indicate prioritization of PSE. The 2018-2019 Union Budget allocated a one-line budget of 75,000 crores (INR 750 billion or USD 10.6 billion) for education for children from age 3 to 17 years (Grade 12) (GOI, n.d.; Mahara, 2019). The increased funding can mitigate Challenges 4 and 5 discussed above. The funding can enhance the quality of the early childhood work force and be used to develop a system of quality assurance and culture of quality enhancement.

Challenge 8: Absence of research on ECCE Linked to poor institutional capacity is the complete absence of data from comprehensive national surveys of ECCE which could provide detailed and accurate figures regarding access and quality of ECCE (Centre for Budget \& Policy Studies, 2018). For example, there is no information about the number of private preschools in the country or the number of children enrolled in them. Furthermore, there is a lack of research that can support the development of evidence-informed ECCE programs. Aside from the national census (conducted every 10 years), the National Family Health surveys that have been conducted sporadically, and the Rapid Survey of Children that was last conducted in 2013-2014, there has not been regular monitoring of the development and learning of nationally representative samples of young children.

The results for the National Family Health Survey- 5 for 17 states and 5 union territories were released in December 2020. Recall that India has 28 states and 8 union territories. Initial findings suggest that while infant mortality rates have decreased in most states, stunting rates for children under 5 years increased in 10 out of 17 states for which data have been released. This is an extremely worrying trend and has implications for nutritional supplementation/school feeding programs within ECCE.

\section{Opportunities}

The Government can fund research that is responsive to policy questions and objectives. There has been an emphasis on evidence-informed policy globally and high quality research has the potential to help understand what policies work and why they do.

\section{Conclusions}

Millions of young children in India are failing to achieve their developmental potential and this paper has considered the context of PSE in India. The government's policies are laudable and in line with international trends. However, there is a big gap between policy and its implementation. There is considerable opportunity for India to meet international and national targets related to PSE. Central to meeting national targets is the enforcement of both the National Education Policy 2020 and quality standards. Statutory regulation and licensing of preschools and mandatory inspection 
processes for monitoring implementation of quality standards are necessary. The increase in public funding to improve infrastructure and educational resources, prioritization of professional development for the early childhood work force, and the use of new technologies and partnerships with the private sector are also essential to ensure equitable access to quality PSE for all children.

\section{Acknowledgements}

Not applicable.

\section{Authors' contributions}

All authors contributed to the conception, analyses, drafting and revising the manuscript. All authors read and approved the final manuscript.

\section{Funding}

The work described in this paper was substantially supported by a grant from the Research Grants Council of the HKSAR, China to Nirmala Rao (Project No. HKU 37000217). The funding body was not involved in the design of the study and collection, analysis, and interpretation of data and in writing the manuscript.

\section{Availability of data and materials}

Data sharing is not applicable to this article as no datasets were generated or analyzed during the current study.

\section{Declarations}

Ethics approval and consent to participate

Not applicable as no data were collected.

\section{Consent for publication}

All authors have read and approved the final manuscript.

\section{Competing interests}

The authors declare that they have no competing interests.

\section{Author details}

${ }^{1}$ Faculty of Education, The University of Hong Kong, Pokfulam Road, Hong Kong, Hong Kong. ${ }^{2}$ University of Delhi, New Delhi, India.

Received: 21 October 2019 Accepted: 28 July 2021

Published online: 10 August 2021

\section{References}

Ainscow, M. (2020). Promoting inclusion and equity in education: Lessons from international experiences. Nordic Journal of Studies in Educational Policy, 6(1), 7-16. https://doi.org/10.1080/20020317.2020.1729587

Alcott, B., Banerji, M., Bhattacharjea, S., Nanda, M., \& Ramanujan, P. (2018). One step forward, two steps back: Transitions between home, pre-primary and primary education in rural India. Compare: A Journal of Comparative and International Education, 50(4), 1-18.

Alcott, B., Bhattacharjea, S., Ramanujan, P., \& Nanda, M. (2019). Participation trends in ECE programs: Who goes where and why? In V. Kaul \& S. Bhattacharjea (Eds.), Early childhood education and school readiness in India (pp. 217-233). Springer.

ASER 2018-Rural. (2019). Annual status of education report (rural). ASER Centre.

Bajaj, M., \& Sharma, S. (2016). Scaling-up early childhood centers for migrant construction workers' children in India. Early Childhood Matters, 125, 74-79. Retrieved from https://bernardvanleer.org/app/uploads/2016/07/Early-Child hood-Matters-2016_13.pdf

Bharti, N. K. (2018). Wealth inequality, class and caste in India, 1961-2012. WID. World Working Paper, 14. https://www. im4change.org/siteadmin/tinymce/uploaded/Wealth\%20Inequality\%20Class\%20and\%20Caste\%20in\%20India\% 201961-2012\%20by\%20Nitin\%20Kumar\%20Bharti.pdf

Bhattacharjea, S., \& Ramanujan, P. (2019). What do children in rural India do in their early years? Retrieved from https:// www.ideasforindia.in/topics/macroeconomics/what-do-children-in-rural-india-do-in-their-early-years.html

Black, M. M., Walker, S. P., Fernald, L. C., Andersen, C. T., DiGirolamo, A. M., Lu, C., McCoy, D. C., Fink, G., Shawar, Y. R., Shiffman, J., \& Devercelli, A. E. (2017). Early childhood development coming of age: Science through the life course. The Lancet, 389(10064), 77-90.

Britto, P. R., Lye, S. J., Proulx, K., Yousafzai, A. K., Matthews, S. G., Vaivada, T., Perez-Escamilla, R., Rao, N., Ip, P., Fernald, L. C., \& MacMillan, H. (2017). Nurturing care: Promoting early childhood development. The Lancet, 389(10064), 91-102.

CARE Ratings. (2018). Overview of the Indian education industry. Retrieved from http://www.careratings.com/upload/ NewsFiles/Studies/Overview\%20of\%20the\%20Indian\%20Education\%20Industry\%20June\%202018.pdf

Centre for Budget and Policy Studies. (2018). Recommendations and policy directions for ECCE in India: Lessons drawn from three reports on ECCE. Bangalore, India. Retrieved from https://cbps.in/wp-content/uploads/Report-4_Recommenda tions-and-Policy-Directions-for-ECCE-in-India-1.pdf 
Chakraborti-Ghosh, S. (2017). Inclusive education in India: A developmental milestone from segregation to inclusion. Journal of Educational System, 1(1), 53-62.

Das, S. \& Kundu, P. (2014). Public investment in young children in India. Retrieved June 6, 2019, from http://www.nationalac ademies.org/hmd/ /media/Files/Activity\%20Files/Children/iYCG/India-Presentations/DasKunduPaper.pdf

Dhingra, R., \& Sharma, I. (2011). Assessment of preschool education component of ICDS scheme in Jammu district. Global Journal of Human Social Science, 11(6), 13-18.

Dixit, S., Sakalle, S., Patel, G. S., Taneja, G., \& Chourasiya, S. (2010). Evaluation of functioning of ICDS project areas under Indore and Ujjain divisions of the state of Madhya Pradesh. Online Journal of Health and Allied Sciences, 9(1).

G20 Development Working Group. (2018). G20 initiative for early childhood development: Building human capital to break the cycle of poverty and inequality.

Government of India. (2009). The right of children to free and compulsory education act, 2009. The Gazette of India: Extraordinary. (Part II, Sec 1. August). Retrieved from https://mhrd.gov.in/sites/upload_files/mhrd/files/upload_document/ rte.pdf

Government of India. (2013a). The national food security act, 2013. The Gazette of India: Extraordinary (Part II, Sec 1. September. Retrieved from http://www.egazette.nic.in/WriteReadData/2013/E_29_2013_429.pdf

Government of India. (2013b). National early childhood care and education (ECCE) policy. Ministry of Women and Child Development. Retrieved from https://wcd.nic.in/sites/default/files/National\%20Early\%20Childhood\%20Care\% 20and\%20Education-Resolution.pdf

Government of India. (2013c). National early childhood care and education (ECCE) curriculum framework. Ministry of Women and Child Development. Retrieved from https://wcd.nic.in/sites/default/files/national_ecce_curr_frame work_final_03022014\%20\%282\%29.pdf

Government of India. (2013d). Quality standards for early childhood care and education (ECCE). Ministry of Women and Child Development. Retrieved from http://www.nipccd-earchive.wcd.nic.in/sites/default/files/PDF/Quality\%20Sta ndards\%20for\%20ECCE.pdf

Government of India. (2014). Decline in child sex ratio. Press Information Bureau. Ministry of Women and Child Development, Government of India. Retrieved from https://pib.gov.in/newsite/PrintRelease.aspx?relid=103437

Government of India. (2015). A quick evaluation study of Anganwadis under ICDS. NITI AAYOG. Programme Evaluation Organisation. Retrieved from https://niti.gov.in/writereaddata/files/document_publication/report-awc.pdf

Government of India. (2016). Rapid survey on children (RSOC): 2013-14. India Fact Sheet. Ministry of Women and Child Development, Government of India and UNICEF. Retrieved from https://wcd.nic.in/sites/default/files/RSOC\% 20FACT\%20SHEETS\%20Final.pdf

Government of India. (2017). Youth in India: 2017. Central Statistics Office, Ministry of Statistics and Programme Implementation, Social Science Division, Government of India. Retrieved from http://mospi.nic.in/sites/default/files/publi cation_reports/Youth_in_India-2017.pdf

Government of India. (2018a). India in figures: 2018. Central Statistics Office, Ministry of Statistics and Programme Implementation, Social Statistics Division, Government of India. Retrieved from http://mospi.nic.in/sites/default/files/ publication_reports/India_in_figures-2018_rev.pdf

Government of India. (2018b). The constitution of India. Ministry of Law and Justice Legislative Department. Retrieved from http://legislative.gov.in/sites/default/files/COI-updated-as-31072018.pdf

Government of India. (2018c). SDG index India, baseline report 2018. NITI Aayog, India. Retrieved from https://niti.gov.in/ content/sdg-india-index-baseline-report-2018

Government of India (2018d). 13.63 lakh Anganwadi Centers (AWCs) of the 14 lakh AWCs sanctioned across the country are operational as on 01.06.2018. Press Information Bureau. Ministry of Women and Child Development, Government of India. Retrieved from http://pib.nic.in/newsite/PrintRelease.aspx?relid=181218

Government of India. (2018e), Guidelines for the implementation of the ICT-RCM system, 2018. Poshan Abhiyaan. Retrieved from https://icds-wcd.nic.in/nnm/NNM-Web-Contents/LEFT-MENU/ICT-RTM/Guidelines_for_ICT-RTM_English.pdf

Government of India. (2019a). Birth rate (5). NITI Aayog, India. Retrieved from https://niti.gov.in/content/birth-rate

Government of India. (2019b). Total fertility rates by residence. NITI Aayog, India. Retrieved from https://niti.gov.in/content/ total-fertility-rate-tfr-birth-woman

Government of India. (2019c). School education. Ministry of Human Resource Development, Government of India. Retrieved from https://mhrd.gov.in/rte_rules

Government of India. (2019d). Umbrella ICDS. Ministry of Women \& Child Development, Government of India. Retrieved from https://wcd.nic.in/schemes-listing/2404

Government of India. (2019e). National Council for Teacher Education. Notification. Norms and standards for four years integrated teacher education programme. The Gazette of India: Extraordinary. (Part III, Sec 4. April). Retrieved from http:// ncte.gov.in/Website/PDF/ANNOUNCEMENT/Gazette\%20Notification\%20of\%20NCTE\%20Regulations\%20(ITEP).pdf

Government of India. (2020). National education policy 2020. Ministry of Human Resource Development, Government of India. (2020). New Delhi: Government of India. https://www.mhrd.gov.in/sites/upload_files/mhrd/files/NEP_Final_ English_0.pdf

Government of India. (n.d.). About Samagra Skiksha. Department of School Education and Literacy, Ministry of Human Resource Development, Government of India. Retrieved from http://samagra.mhrd.gov.in/about.html

Government of India. (n.d.). Regulatory guidelines for private play schools. National Commission for Protection of Children's Rights, Government of India. Retrieved from https://ncpcr.gov.in/showfile.php?lang=1\&level=1\&\&sublinkid=933\& lid $=1271$

HAQ Centre for Child Rights. (2019). Union budget 2018-1019: budget for children in \#New/ndia. http://haqcrc.org/wpcontent/uploads/2018/02/haq-budget-for-children-2018-19.pdf

Hazarika, G., \& Viren, V. (2013). The effect of early childhood developmental program attendance on future school enrollment in rural North India. Economics of Education Review, 34, 146-161.

International Institute for Population Sciences (IIPS) and ICF. (2017). National family health survey (NFHS-4), 2015-16, India. Mumbai: IIPS. Retrieved from https://dhsprogram.com/pubs/pdf/FR339/FR339.pdf 
Kaul, V. (2019a). Introduction: Positioning school readiness and early childhood education in the Indian context. In V. Kaul \&S. Bhattacharjea (Eds.), Early childhood education and school readiness in India (pp. 3-18). Springer.

Kaul, V. (2019b). Research in India on early childhood education and school readiness: Some learnings. Early childhood education and school readiness in India (pp. 19-32). Springer.

Kaul, V., Bhattacharjea, S., Chaudhary, A. B., Ramanujan, P., Banerji, M., \& Nanda, M. (2017). The India early childhood education impact study. UNICEF.

Kaul, V., \& Sankar, D. (2009). Early childhood care and education in India. National University of Educational Planning and Administration (NUEPA).

KMPG. (2019). Transforming the Anganwadi ecosystem: Next generation early childhood development interventions in India. Retrieved from https://assets.kpmg/content/dam/kpmg/in/pdf/2019/03/early-childhood-development-angan wadis-icds-ecosystem.PDF

Krishnakumar, G. (2016, December 16). Fine-tuning education for society's youngest. The Hindu. Retrieved from https:// www.thehindu.com/news/national/Fine-tuning-education-for-society\%E2\%80\%99s-youngest/article16842240.ece

Lu, C., Black, M. M., \& Richter, L. M. (2016). Risk of poor development in young children in low-income and middle-income countries: An estimation and analysis at the global, regional, and country level. The Lancet Global Health, 4(12), e916-e922.

Mahara, P. (2019). Let child budget share increase in the upcoming Union Budget. Daily O. Retrieved from https://www. dailyo.in/variety/child-relief-you-union-budget-2019-education-children-s-safety-children-s-welfare/story/1/29118. html

McCoy, D. C., Zuilkowski, S. S., Yoshikawa, H., \& Fink, G. (2017). Early childhood care and education and school readiness in Zambia. Journal of Research on Educational Effectiveness, 10(3), 482-506.

National Institute of Public Cooperation and Child Development (NIPCCD). (2006). Three Decades of ICDS_An appraisal. New Delhi: Government of India. Retrieved from http://www.nipccd.nic.in/reports/eicds.pdf

National Institute of Public Cooperation and Child Development. (2012). Study on monitoring strategy of preschool education component under ICDS, research studies 2011-12. NIPCCD.

Nayar, K. R. (2007). Social exclusion, caste \& health: A review based on the social determinants framework. Indian Journal of Medical Research, 126(4), 355.

Nores, M., \& Barnett, W. S. (2010). Benefits of early childhood interventions across the world: (Under) investing in the very young. Economics of Education Review, 29(2), 271-282.

Nurturing Care for Early Childhood Development (2018). Country profiles: India. Retrieved June 5, 2019, from https://nurtu ring-care.org/wp-content/uploads/2018/10/India.pdf

Pande, R., \& Malhotra, A. (2006). Son preference and daughter neglect in India. International Center for Research on Women.

Pandya, K. (2018). The National Early Childhood Care and Education Curriculum Framework, 2014, and its implications for practice. In Voices of Teachers and Teacher Educators, Vol. VI (II), pp. 20-27. National Council of Educational Research and Training, India. Retrieved from http://ncert.nic.in/publication/journals/pdf_files/Noices_Feb_18.pdf

Pratham (2019). Early childhood education. Retrieved August 8, 2019, from http://pratham.org/programs/education/earlychildhood-education/

Rao, N. (2005). Children's rights to survival, development and early learning in India: The critical role of the integrated child development services program. International Journal of Early Childhood, 37(3), 15-31.

Rao, N. (2010). Preschool quality and the development of children from economically disadvantaged families in India. Early Education and Development, 21(2), 167-185.

Rao, N., \& Kaul, V. (2018). India's integrated child development services scheme: challenges for scaling up. Child: Care, Health and Development, 44(1), 31-40. https://doi.org/10.1111/cch.12531

Rao, N., \& Sun, J. (2010). Early childhood care and education in the Asia-Pacific region: Moving towards Goal 1 (p. 97). Comparative Education Research Centre, The University of Hong Kong/UNESCO.

Rao, N., \& Sun, J. (2015). Quality early childhood care and education in low resource level countries in Asia. In P.T. M. Marope \&Y. Kaga (Eds.), Investing against evidence: The global state of early childhood care and education (pp. 211-230). UNESCO.

Rao, N., Sun, J., Chen, E. E., \& Ip, P. (2017). Effectiveness of early childhood interventions in promoting cognitive development in developing countries: A systematic review and meta-analysis. Hong Kong Journal of Paediatrics (new Series), 22(1), 14-25.

Rao, N., Sun, J., Pearson, V., Pearson, E., Liu, H., Constas, M. A., \& Engle, P. L. (2012). Is something better than nothing? An evaluation of early childhood programs in Cambodia. Child Development, 83, 864-876. https://doi.org/10.1111/j. 1467-8624.2012.01746.x

Sanneving, L., Trygg, N., Saxena, D., Mavalankar, D., \& Thomsen, S. (2013). Inequity in India: The case of maternal and reproductive health. Global Health Action, 6(1), 19145. https://doi.org/10.3402/gha.v6i0.19145

Singh, R. \& Mukherjee, P. (2017). Comparison of the effects of government and private preschool education on the developmental outcomes of children: Evidence from Young Lives India. Young Lives. Retrieved from https://www.young lives.org.uk/sites/www.younglives.org.uk/files/YL-WP167-Singh\%20\%281\%29.pdf

UN Sustainable Development Solutions Network (SSDN). (2014). Sustainable development goals, targets and indicators. Leadership Council, UN SDSN.

UNDP. (2017). Human development report: Human development data (1990-2017). Retrieved from http://hdr.undp.org/en/ data/query

UNESCO. (2011). Word data on education. India. VII Ed. 2010/11. UNESCO International Bureau of Education. Retrieved from http://www.ibe.unesco.org/fileadmin/user_upload/Publications/WDE/2010/pdf-versions/India.pdf

UNICEF. (2017). The state of the world's children 2017: Children in a digital world. Retrieved from https://www.unicef.org/ sowc2017/

World Bank (2019a). India. Retrieved from https://data.worldbank.org/country/india

World Bank (2019b). Country profile: India. Retrieved from https://databank.worldbank.org/data/views/reports/repor twidget.aspx?Report_Name $=$ CountryProfile\&ld=b450fd57\&tbar=y\&dd=y\&inf =n\&zm =n\&country=IND 
Yoshikawa, H., Leyva, D., Snow, C. E., Treviño, E., Barata, M., Weiland, C., Gomez, C. J., Moreno, L., Rolla, A., D'Sa, N., \& Arbour M. C. (2015). Experimental impacts of a teacher professional development program in Chile on preschool classroom quality and child outcomes. Developmental Psychology, 51(3), 309-322.

\section{Publisher's Note}

Springer Nature remains neutral with regard to jurisdictional claims in published maps and institutional affiliations.

Submit your manuscript to a SpringerOpen ${ }^{\circ}$ journal and benefit from:

- Convenient online submission

- Rigorous peer review

- Open access: articles freely available online

- High visibility within the field

- Retaining the copyright to your article

Submit your next manuscript at $>$ springeropen.com 